\title{
Editorial
}

\section{Brands and ethics - oil and water?}

In this issue of this journal there is a paper by Dr Rosamund Thomas in which she sets out an argument that brands and especially corporate brands need to factor in an ethical stance to be successful. I strongly agree with this thesis but I am less convinced that statutory measures have a very strong role to play.

I will return to the issue of legislation, but first let us consider how much of an issue ethics are for brands.

\section{BRAND ETHICS}

There is no doubt that ethics are an increasing concern for brands, especially at the corporate brand level. This is because people are engaging with brands in two modes, as consumers and as citizens. It is primarily in the citizen mode that issues of ethics are critical.

First, let me define the two terms consumer and citizen. As a consumer, people make decisions in the immediate context of the purchase situation where they are often under pressure and focused on the purchase experience itself. In the mode of citizen, however, the immediate pressures and concerns of the purchase situation are removed and therefore the individual can adopt considered behaviour. Let me give you an example. A consumer, running dangerously low on gasoline, buys some fuel from a Shell service station. Two days earlier this same individual had read about the proposed dumping at sea of Brent Spar and had vowed not to buy Shell fuel. The next time he or she makes a non-emergency purchase, Shell will not be the brand of choice but the view is not held so strongly that he or she will risk running out of gasoline.
I believe that the evidence we have from a number of consumer research projects at The Value Engineers points strongly to the conclusion that this citizen mode of behaviour is growing. As the world becomes more information rich and as the channels of communication fragment it is extremely hard to keep people under informed. Equally, phenomena like increased levels of higher education, greater penetration of share ownership and higher levels of single issue campaigning are encouraging people to think about companies rather than individual products and to take a more holistic view of an organisation and its impact on society. This coincides with a rise in prominence of the corporate brand as we progress towards a service and high technology based economic model.

CEOs and those concerned with corporate marketing need to understand how the issue of ethics will impinge on the brand.

This means being constantly attuned to the issues citizens believe to be important at any moment in time. The key issue to understand is that over time these issues change both in nature and intensity. Some of the current hot topics are employment practices (especially in developing countries), technology applications, green credentials, animal husbandry/animal testing and investment back into the wider community.

The important change in attitude at the corporate level is to now get involved in these debates and to be seen to be engaged with the issues rather than stonewalling. One of the early examples of this engagement with difficult issues was the creation of the Sellafield visitor centre in Cumbria in the UK. What Sellafield did was to put some 
sanity and perspective into the polarised debate about the role of nuclear power in civil applications. The Sellafield centre was targeted at people in their citizen mode and it worked extraordinarily well. The debate about the civil application of nuclear technology has now matured to the point where British Energy could be floated on the stockmarket and where future decisions about the application of the technology are transparent to the market and to the consumer. This does not mean that nuclear technology has a green light for the future but it does mean that the decisions taken about nuclear power will be informed and driven by the market in its broadest sense.

Another groundbreaking engagement with the issues is Monsanto's recent advertising campaign addressing the issues of the application of biotechnology in agri-business and the food processing business.

These are encouraging signs that the citizen is being taken seriously.

\section{WHOSE ETHICS SHOULD DETERMINE CORPORATE BEHAVIOUR?}

At the highest level, there are only two powerful sources of influence, the citizen or government. Dr Thomas advocates that government should legislate for corporate ethics but this raises some substantial dilemmas.

First, ethics change. As soon as a sweeping ethical code is enshrined in legislation it is likely to be out of date.

We should also ask whether governments are capable of encouraging companies to be any more ethical than they are themselves. In the UK, the government's behaviour with Windscale/Sellafield/Dounreay, the BSE crisis and the questionable relationship between government policy and individual companies shows how open to influence and partial views government is.

UK government has no tradition of putting the consumer ahead of industry's needs - in fact, the opposite is true. It is also highly debatable whether governments could credibly advocate that corporations embrace greater openness and higher ethical standards than they themselves operate by.

How much better it is to encourage consumers to act as citizens and to vote with their wallets. Surely, the proper role of government is to encourage people to take responsibility for their own actions as consumers. There is no unethical behaviour that cannot be rejected or punished by an informed consumer.

Legislation thus has a role at the single issue level but not at the level of overall corporate behaviour. This means, for instance, that setting technical standards for the quality of drinking water is a useful role for government whilst saying that corporations should at all times act 'ethically' is extremely questionable.

There are many further problems with legislation.

At what point could single jurisdiction legislation be judged to be an acceptable manifestation of cultural imperialism? Would government-imposed ethics in a European economy have the same relevance or value in an Islamic country? Would the ethics of, say, an extremely right wing or xenophobic culture be ones that a US company would want to uphold in that particular market? One person's ethics are another person's poison one might say.

Would legislation encourage companies to adhere to the letter rather than the spirit of the law? At what point would legislation be perverted by governments trying to protect indigenous industries at the expense of incomers?

The tobacco industry throws up some of these dilemmas in high relief. Every con your health. A significant minority of consumers continues to purchase cigarettes. Are the tobacco companies operating unethically? Is it unethical to sell a product that informed consumers want to buy? Is the 
tobacco industry any more or less ethical than the oil industry or the alcoholic beverages industry? These are questions that legislation will find difficult to answer.

\section{DOES THE MARKET PUNISH UNETHICAL BEHAVIOUR?}

What is the 'market' in this case? The market as I mean it here is both the market as defined by the consumer and the market for a company's shares as defined by stockholders.

The market is, of course, an imperfect mechanism but there are encouraging signs that it can and will punish unethical behaviour. Let me cite a few examples where either consumer behaviour has changed or the market has downrated an 'unethical' business.

First, during France's recent testing of nuclear warheads in the Pacific there was significant rejection of French products, especially wine, in certain territories. This had a real effect on French policy and reminded the French government that what is acceptable to French voters is not acceptable to world consumers.

Shell was forced to change its attitude to the disposal of deep water exploration rigs and UK life assurance and pension providers have been strongly downrated on the stockmarket because of the pensions mis-selling scandal.

Monsanto has found that European consumers and citizens are less acquiescent about an unproven technology (biotechnology) than US citizens and has slowed its introduction of bio-engineered products whilst engaging in an open debate about its merits.

These examples show the potential power of the market and the citizen in ensuring ethical behaviour.

\section{MANAGING ETHICS INTO CORPORATE BRANDS}

The key to ensuring that brands behave ethically is to ensure that individuals are encouraged to see that every purchase decision they make has an ethical dimension. If individuals support unethical companies they have nobody to blame but themselves in a modern, open and liberal society.

Likewise, shareholders should also act with ethical dimensions in mind. The launch of ethical funds for the retail investment industry is a good example of this.

From a corporate branding perspective, executives need to be mindful that increasingly there is a fusion between the consumer and the citizen mode and that this will mean no retreat from more corporate transparency and dialogue with the customer. The consumer as citizen is a far more complex animal to understand and persuade.

Most consumer-facing companies in developed economies, in my experience both as a client and as a consultant, try to behave ethically. Conscious deviation from this standard is rare. Yet this is not to suggest that companies should be complacent. It is vital to take a read on all the ethical issues that face a corporation and be proactive in addressing them openly.

So my conclusion is that in a modern, liberal society legislating for ethics in business is irrelevant whilst campaigning for individuals to act responsibly and with discrimination as consumers is an extremely important priority.

Caveat emptor, floreat emptor.

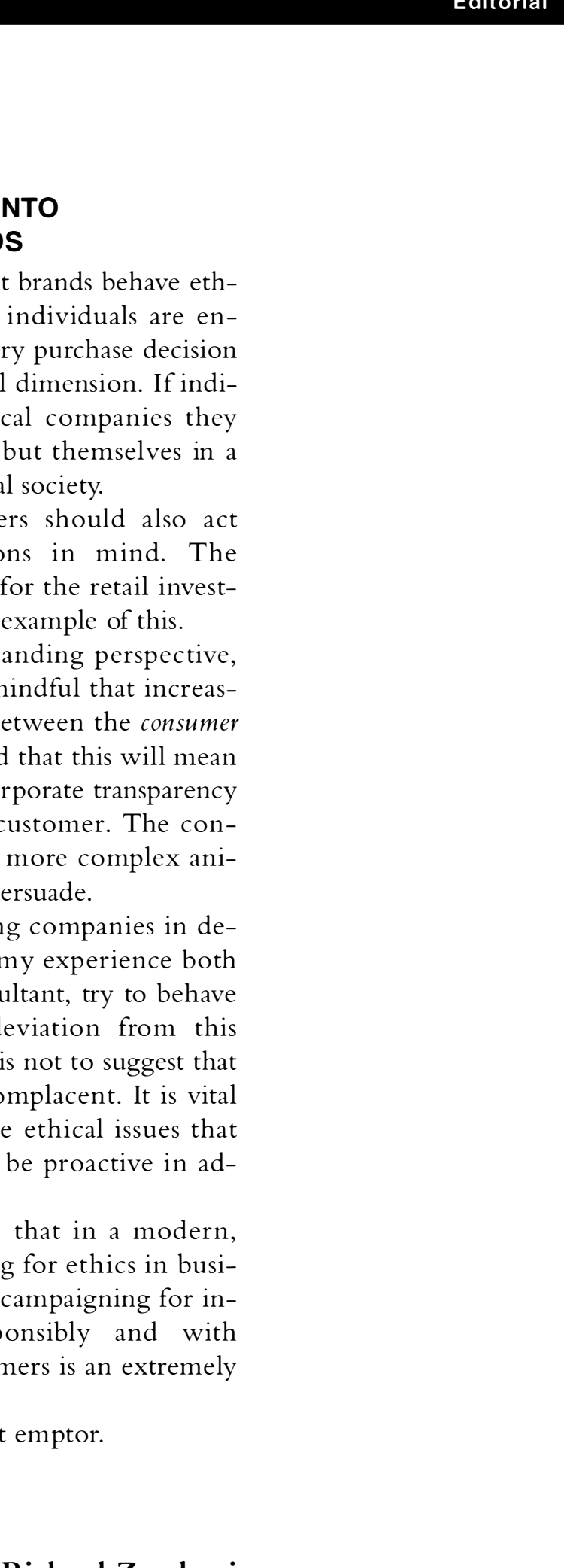

Richard Zambuni Editorial Board 